\title{
Alignment monitoring system for the PIP-II cryomodules

\section{ALIGNMENT REQUIREMENTS}

The alignment of the SSR1 cryomodule components was studied as the acceptable beam deflection, offset and defocusing, which may otherwise cause beam loss. Simulations and measurements established that the maximum deviations of the vacuum chamber from the reference orbit should not exceed $5 \%$ of the beam aperture.

\begin{tabular}{lll} 
& SSR1/HB650 & Solenoid \\
\hline Angular error RMS, [mrad] & $<10$ & $<1$ \\
Transverse error RMS, [mm] & $<1$ & $<0.5$
\end{tabular}

PIP-II Technical Requirements Specification

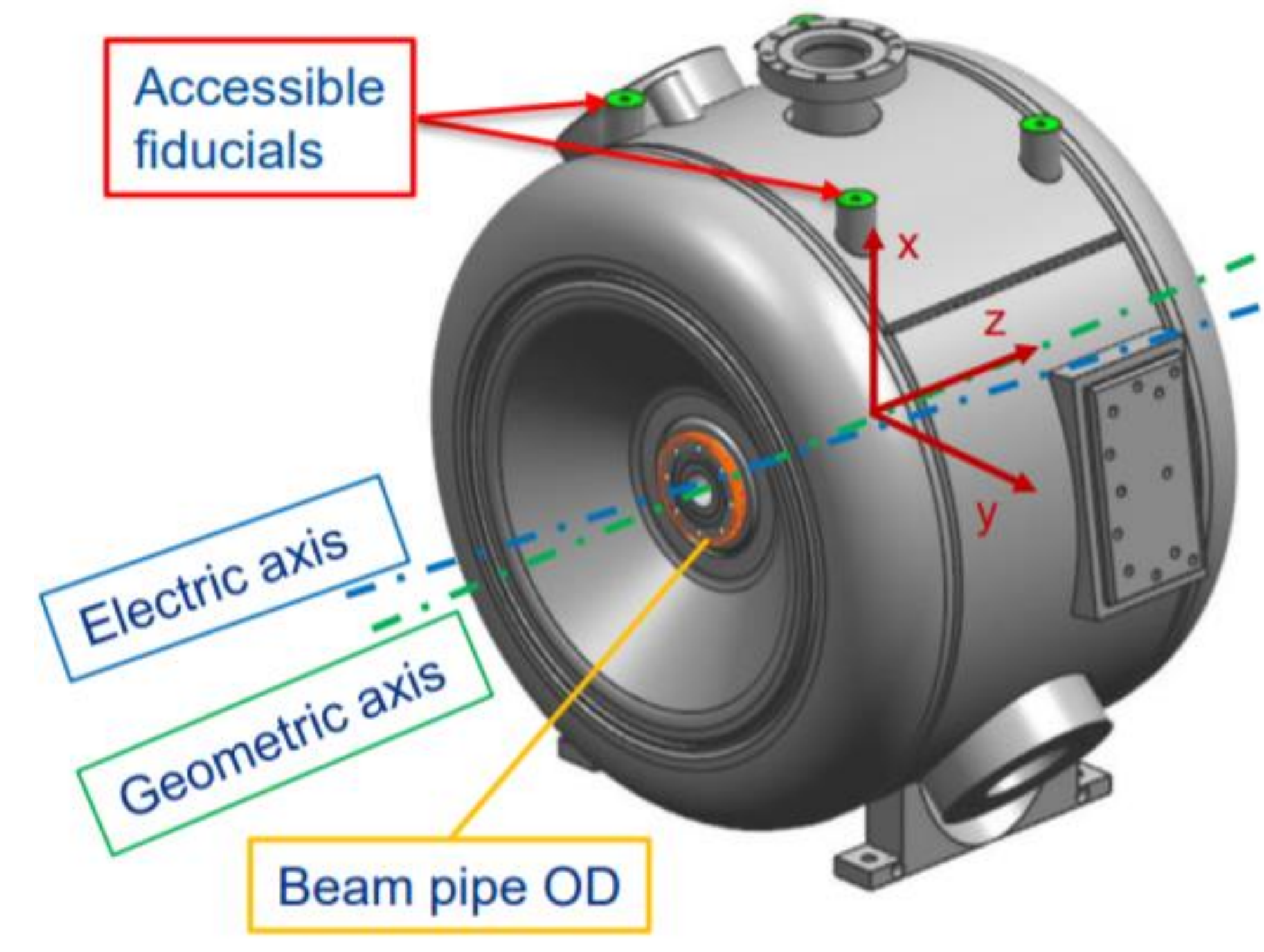

SSR1 - Cavity Resonator

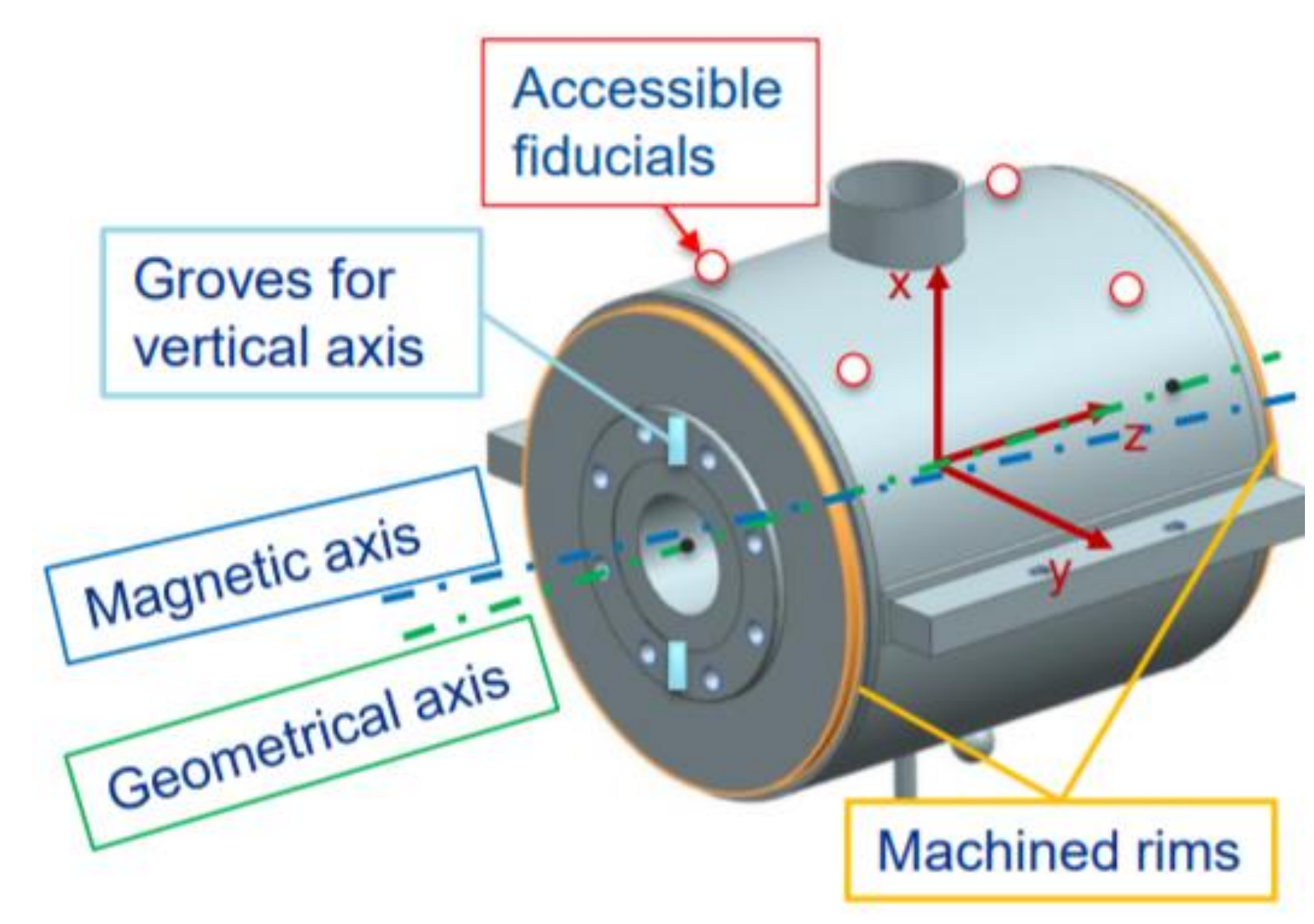

Solenoid - Focusing Lenses

\section{ALIGNMENT STRATEGY}

- Alignment monitoring through optical targets installed on the internal assembly

- The target position is observed by monitoring cameras (HBCAM), installed on the two outside ends of the cryomodule

- As a design choice we monitor only relative movements of the cryomodule components and have as a calibrated distance the difference between two glass balls.

\section{MECHANICAL DESIGN}

- Each SSR1 cryomodule includes eight cavities and four focusing lenses, with a total of 12 elements to be monitored.

- 96 glass balls are located in spatial distribution in order to not over shadow each over and allow full camera view of the target pattern

- The target tube is machined with rectangular slot and allow glass balls being seen from both sides

- The frame can be adjusted vertically as well as horizontally. Once the position established target frames are locked inside the survey base

\section{MEASUREMENT PRINCIPLE}

- Image reading on CCD sensors

- The camera measures the angular separation of two sources (high reflective index glass balls)

$$
\boldsymbol{\beta}=\boldsymbol{d} / \boldsymbol{r}=\boldsymbol{s} / \boldsymbol{c}
$$

- $c$ is the distance from the camera to the CCD sensor and is a calibrated distance - $d$ is the separation between two targets, this must be a calibrated dimension

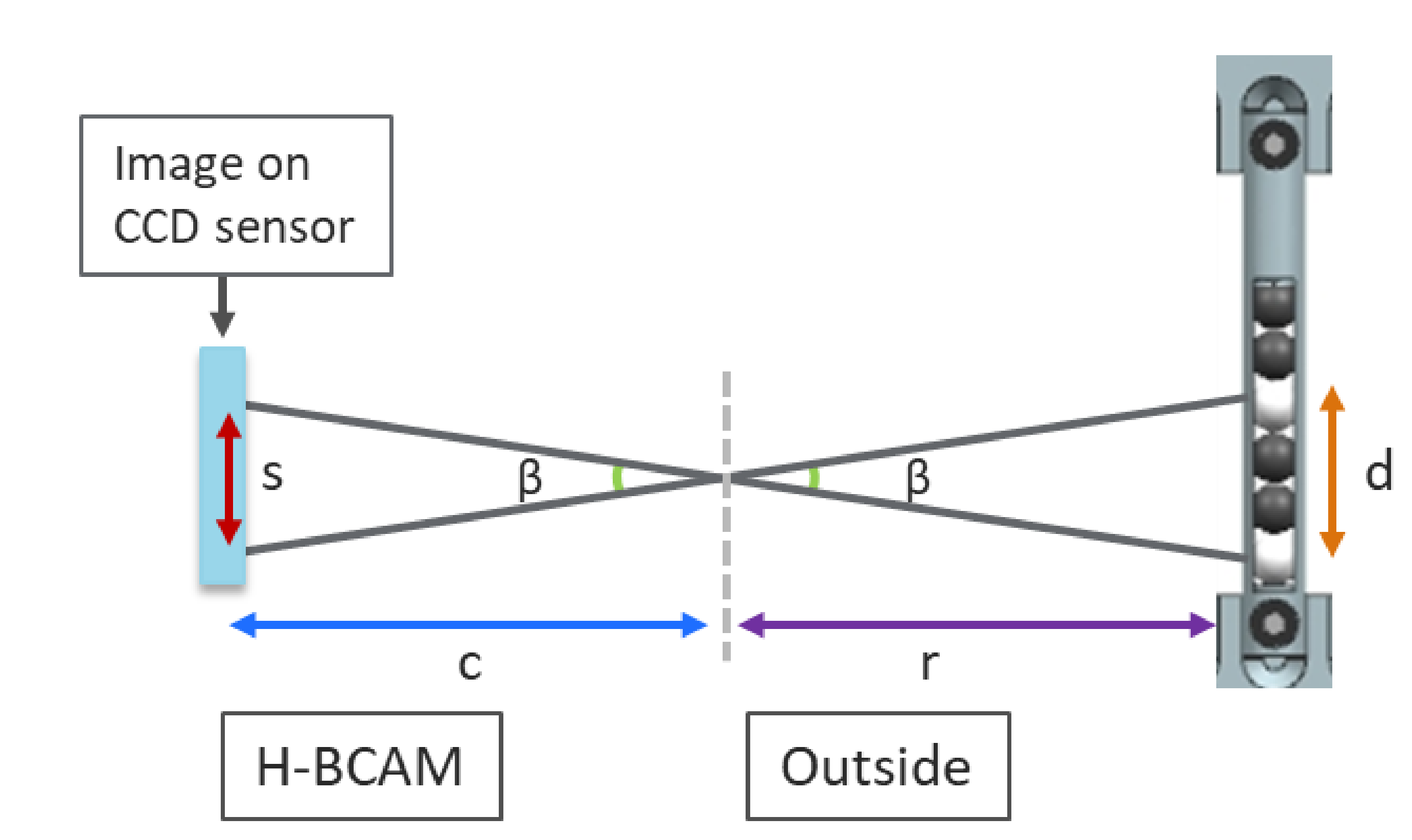

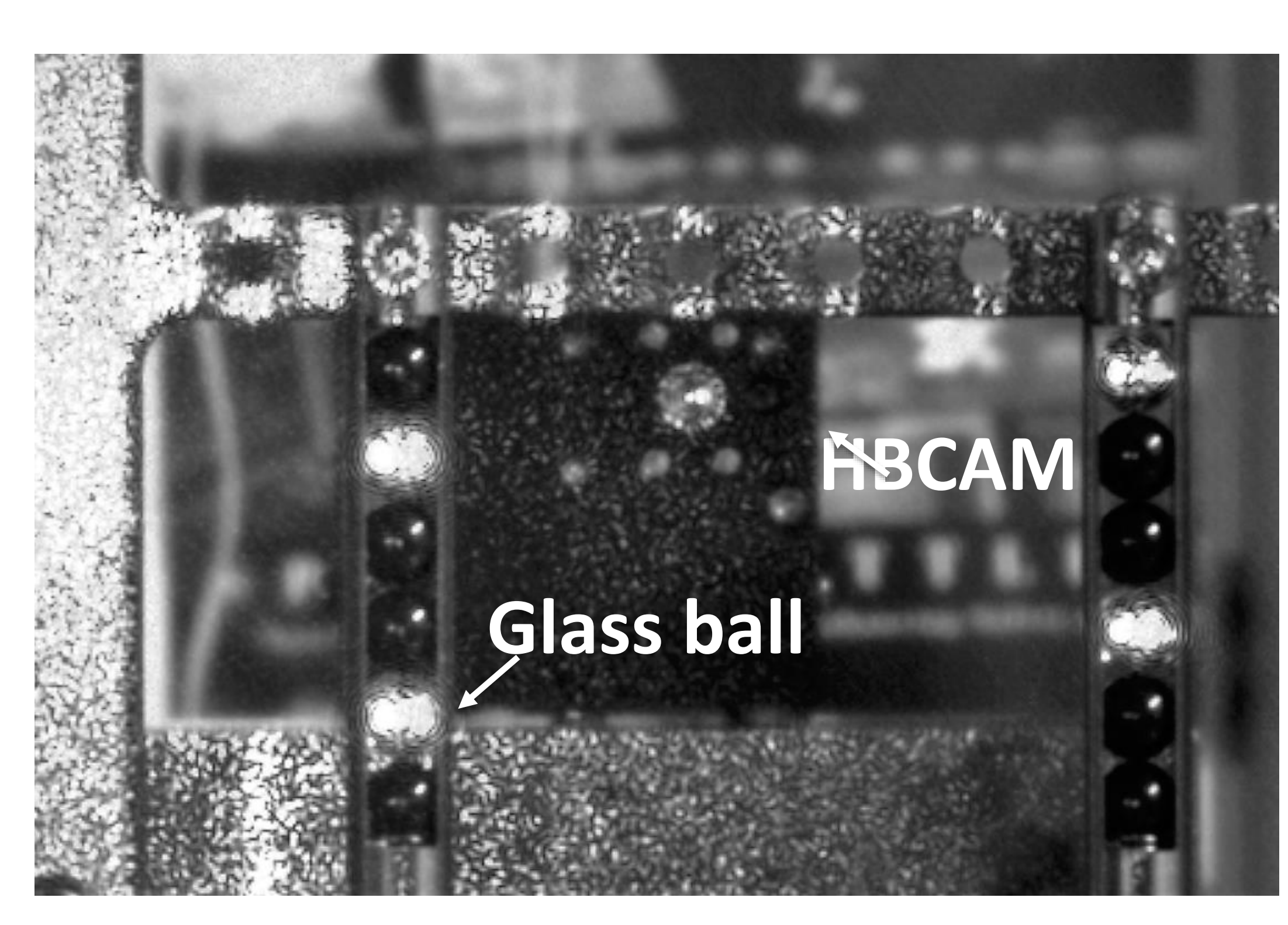

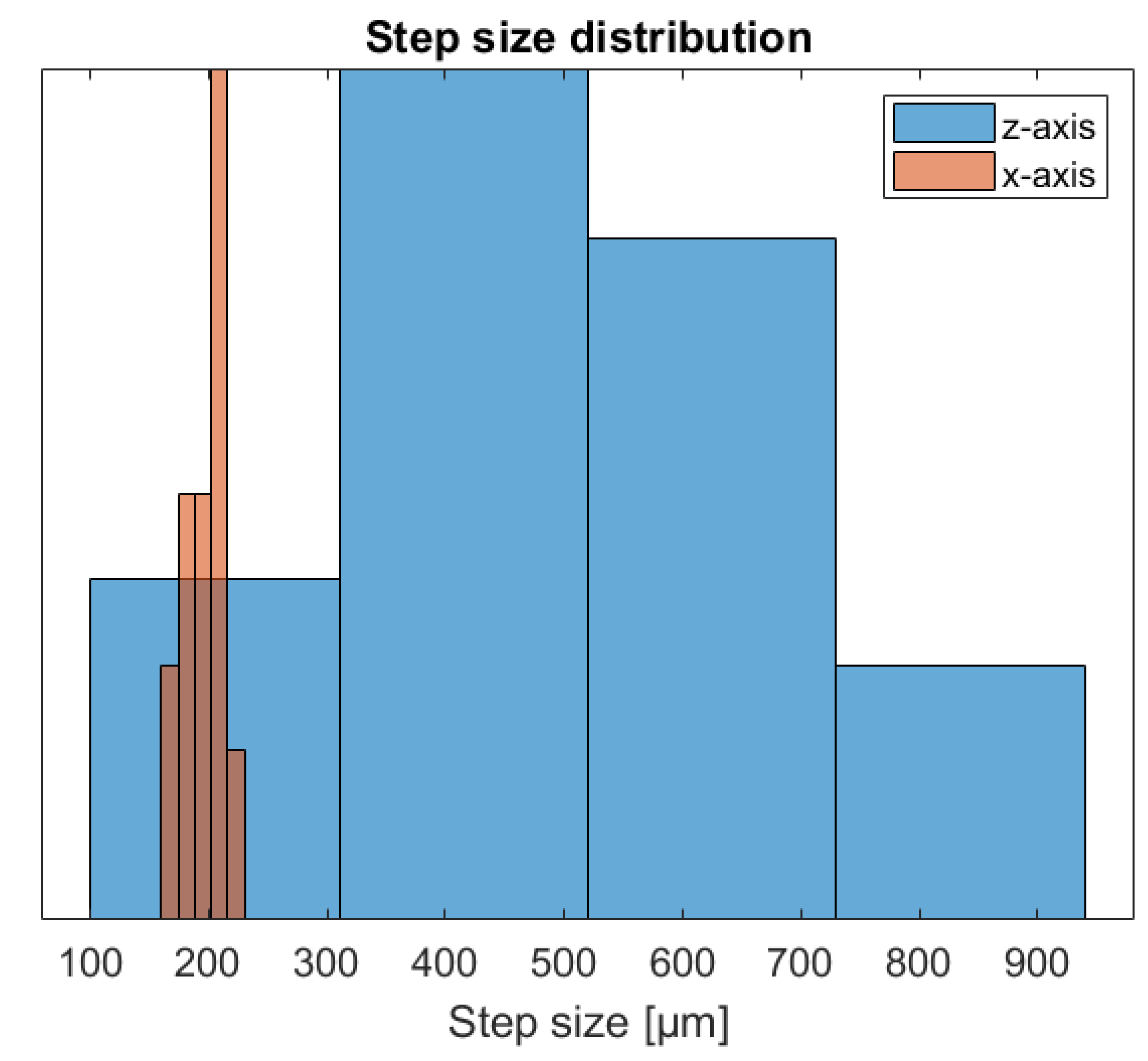

\begin{tabular}{|l|l|l|l|}
\hline & \multicolumn{3}{|c}{ x-axis } \\
\hline Step size, [mm] & 0.2 & 0.1981 & 0.0004 \\
\hline Relative error, [\%] & & 1.25 & 0.84
\end{tabular}

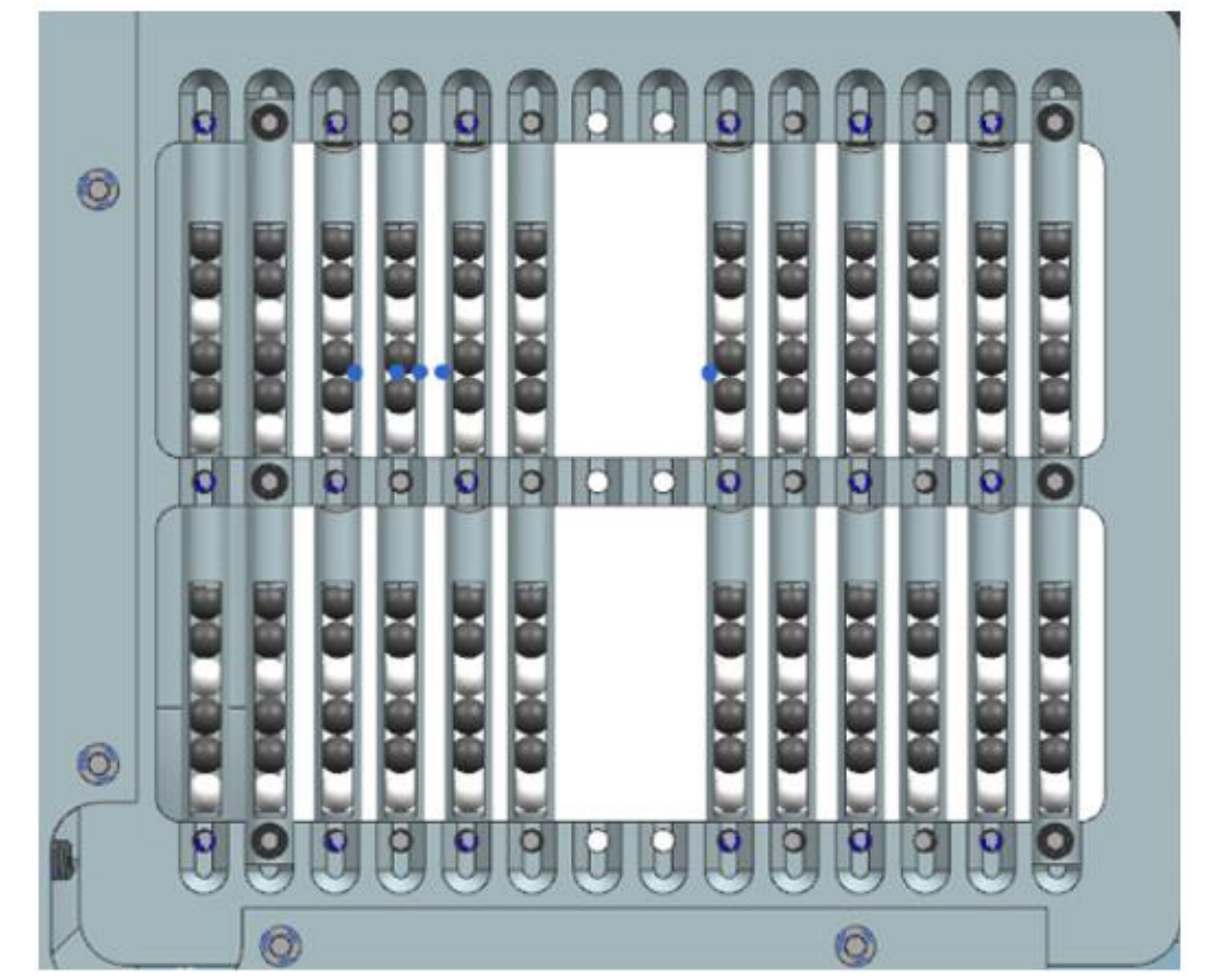

Full target frame as seen from the camera

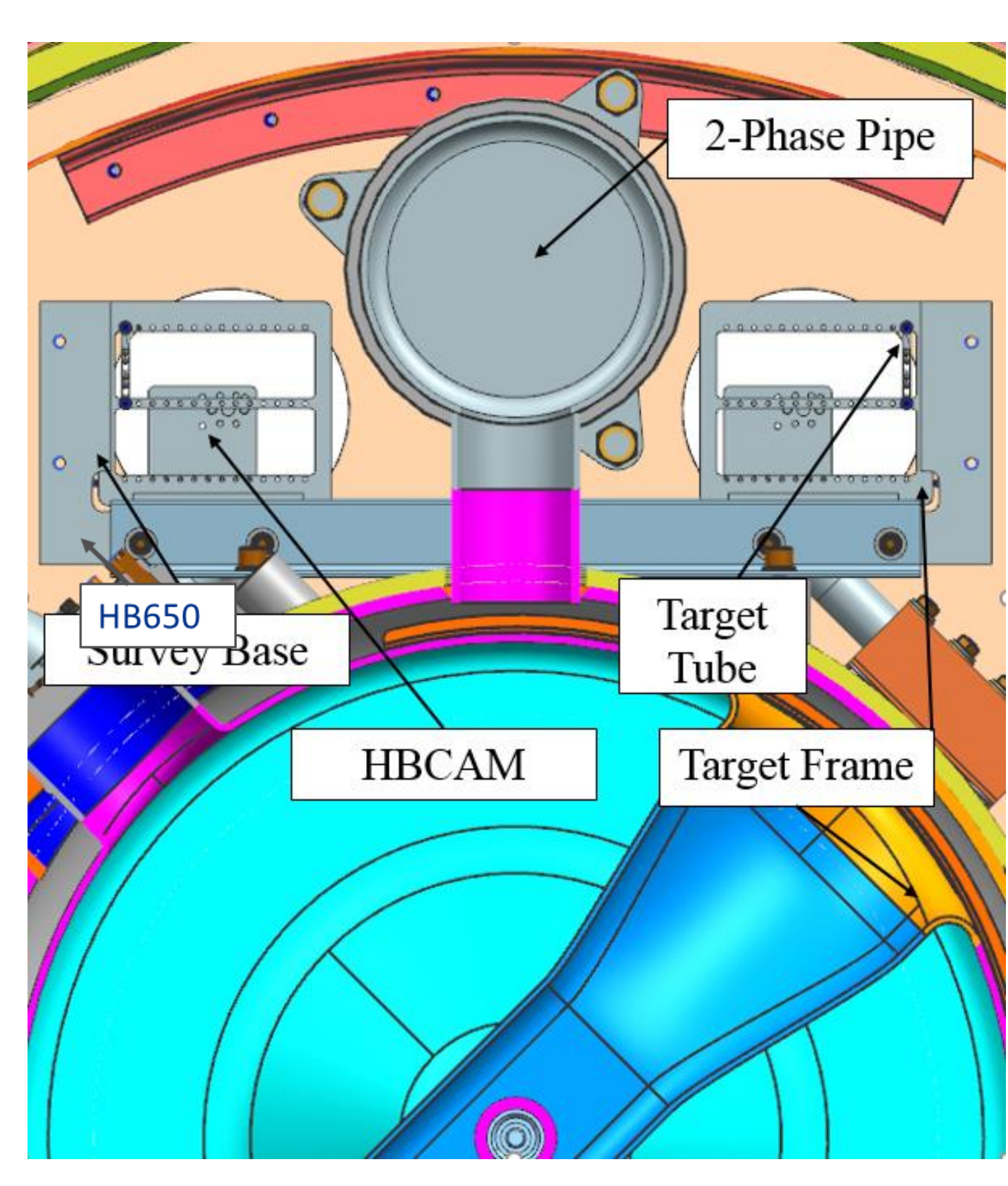

Cryomodule cross-section

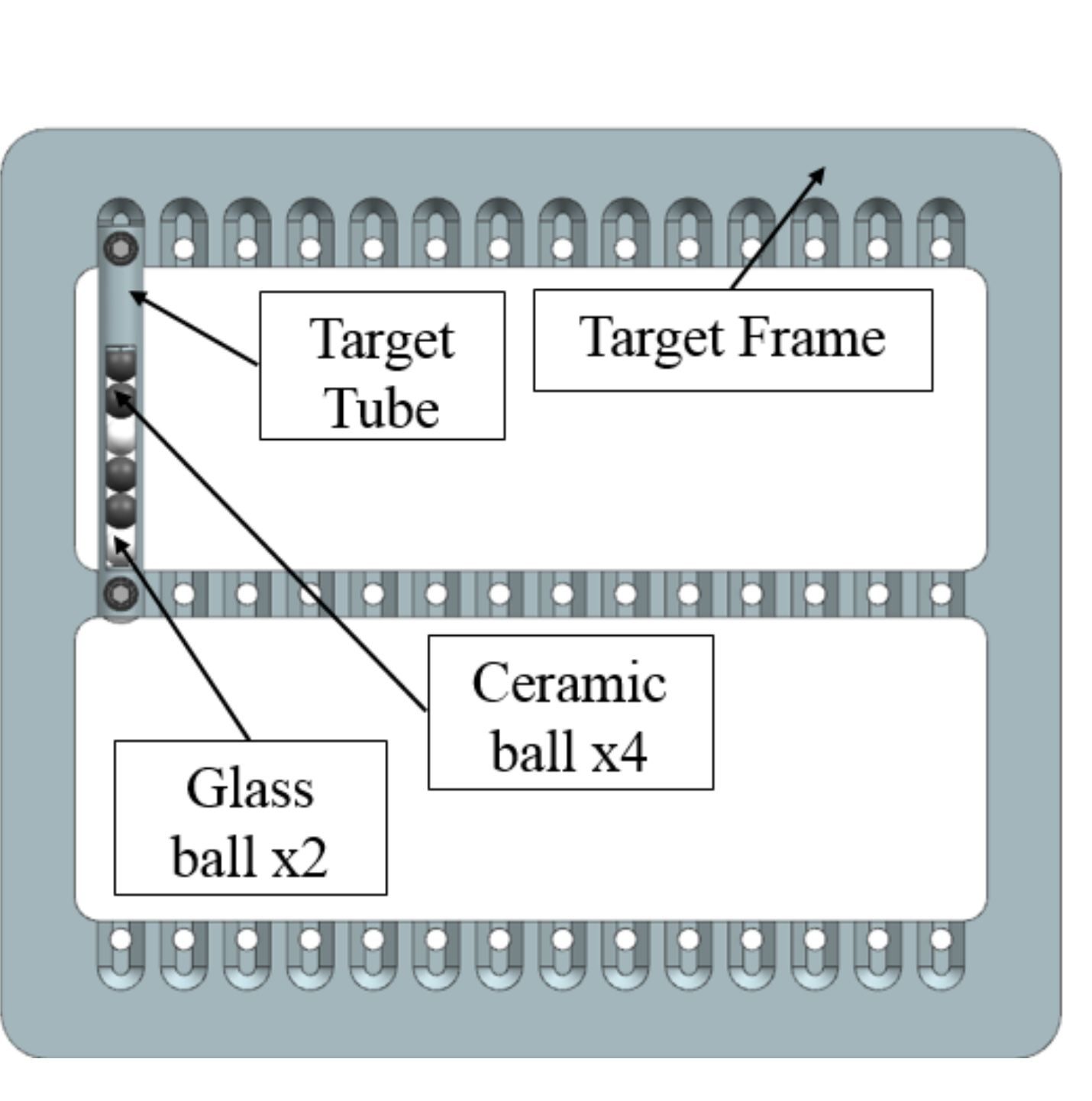

Individual target frame mounted on each component cross section

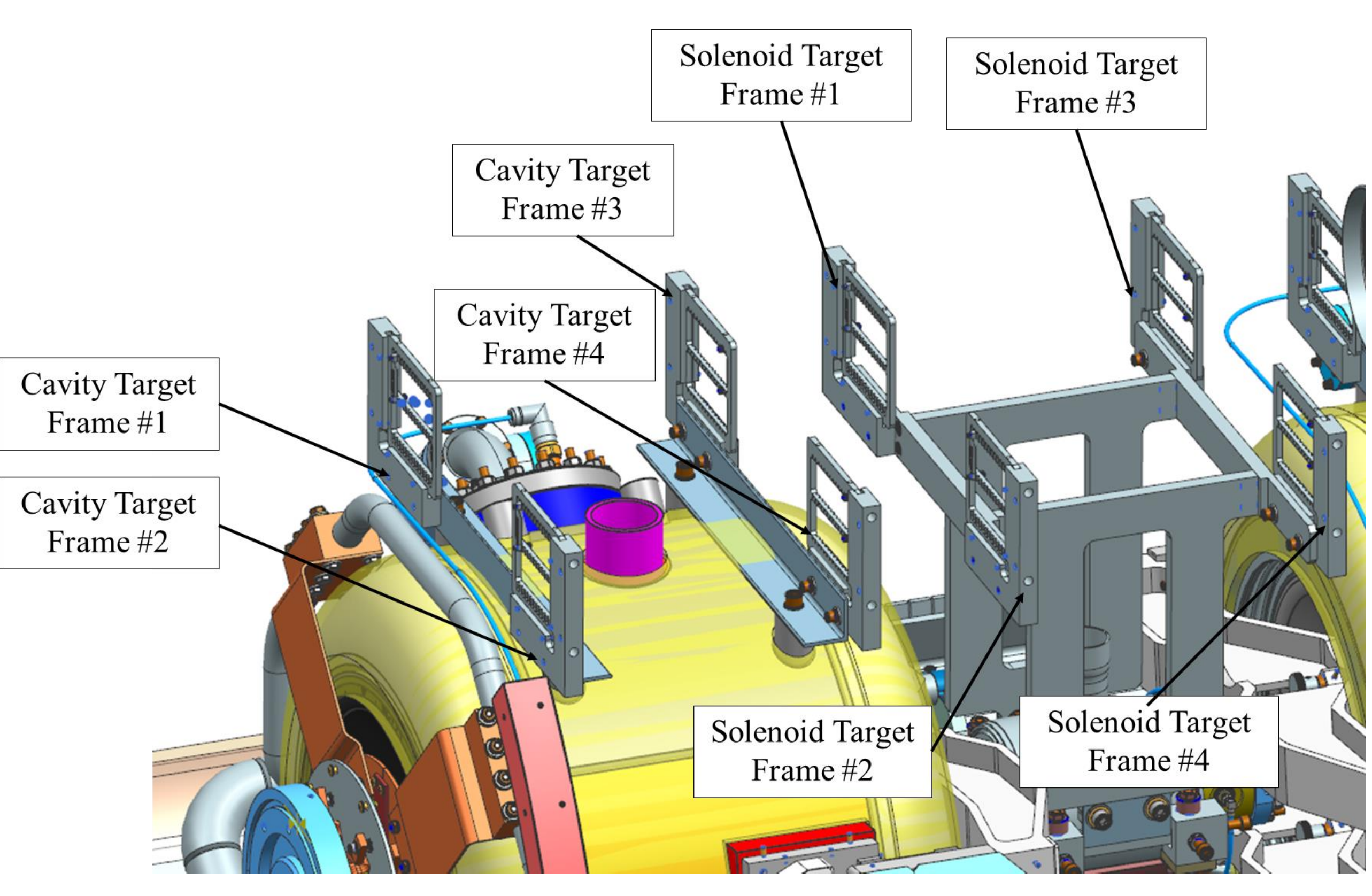

Cryomodule coldmass view

Target tub

Target tube
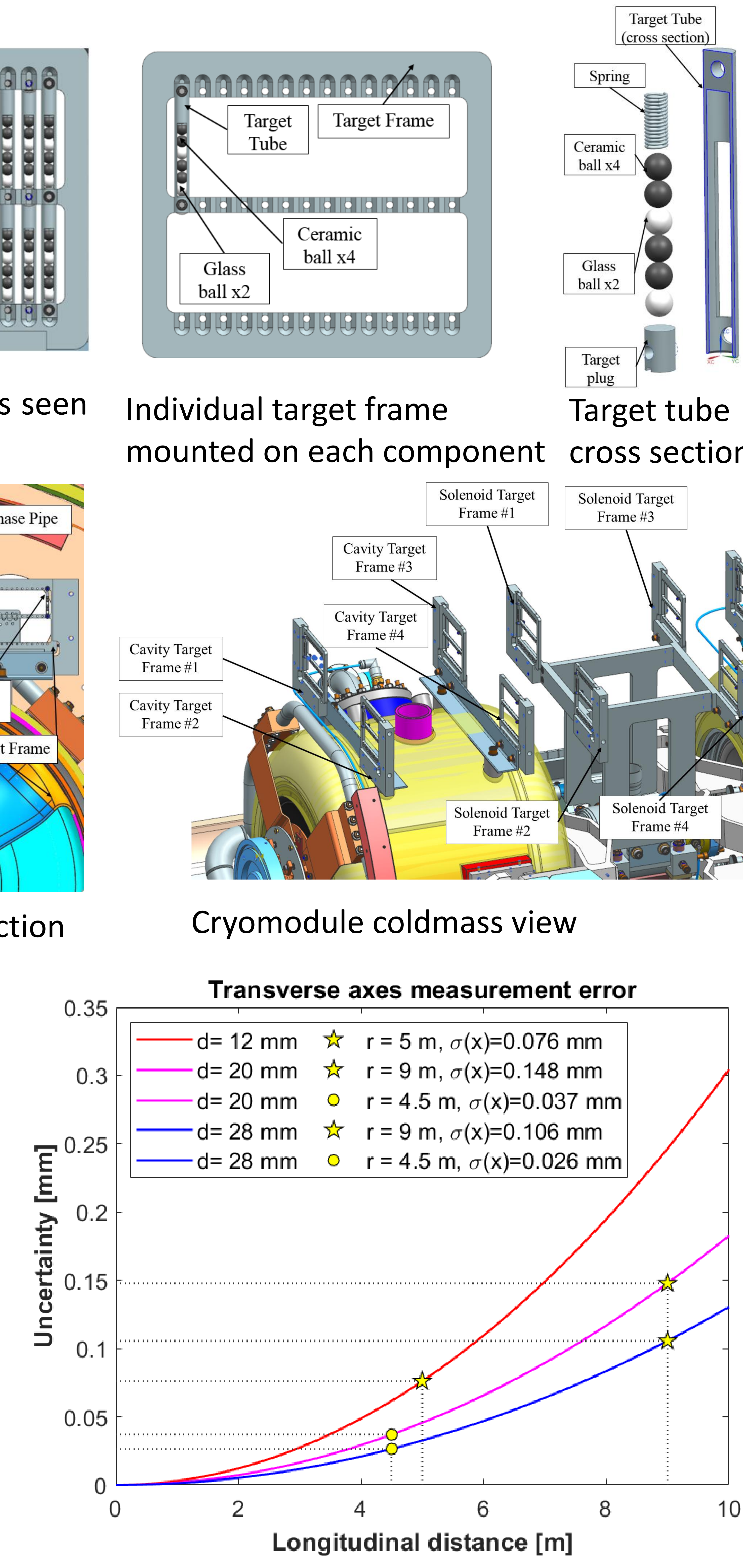

PERFORMANCES EVALUATION

- Targets mounted on translation stages, moving the transverse horizontal direction ( $x$-axis)

- The results are validated through a CMM (Coordinate Measuring Machine)

We observe a good agreement between the independent measurements of the HBCAM and the CMM, with sub-micrometric error on the $\mathrm{x}$-axis. 